ISBN 978-93-86878-07-6

16th IIE International Conference on Computer, Control and Communication Engineering

(IC4E'2017)

Dubai (UAE) Dec. 21-22, 2017

\title{
X-shaped Circularly Polarized Aperture Coupled Antenna for WLAN
}

\author{
Mohammed Amin Meriche ${ }^{1,2} *$, Abderraouf Messai ${ }^{1}$, Boualem Hammache ${ }^{1}$ and Tayeb. A. Denidni ${ }^{2}$ \\ ${ }^{1}$ Department of Electronics, Université des frères Mentouri, Constantine, Algeria \\ ${ }^{2}$ EMT-INRS, Institut national de la recherche scientifique, 800, rue De La Gauchetière O, \\ Montréal (Qc) H5A 1K6 Canada
}

\begin{abstract}
This paper presents a new compact aperture-coupled circularly polarized (CP) antenna for WLAN applications. The new designed antenna consists of $X$-shaped slot rotated by $45^{\circ}$ with unequal arms etched on a circular microstrip antenna fed through the coupling between the ring slot and the microstrip line. The circular polarization is obtained due to the unequal $X$-shaped slot arms. The antenna with overall size of $60 \times 60 \times 5.83$ $\mathrm{mm}$ has a 10-dB impedance bandwidth of 30\% (4.8-6.5 GHz), a $3 \mathrm{~dB}$ AR bandwidth of 3.47\% (5.67-5.87 GHz) and 3-dB gain bandwidth of $46.62 \%(4.08-6.56 \mathrm{GHz})$ with a peak gain of $8.85 \mathrm{dBi}$.
\end{abstract}

Keywords: Aperture-coupled, circularly polarized (CP), X-shaped slot.

\section{Introduction}

Circularly polarized patch antenna has attracted significant attention in modern wireless communication systems and offer many advantages such as more flexibility in the orientation of transmitting and receiving antennas and polarization mismatch reduction compared to linear polarization [1]-[5]. Several methods have been proposed to design the single-feed aperture-coupled antenna with circular polarization $(\mathrm{CP})$. The aperturecoupled antennas were designed and developed for broadband, high gain, circular polarization and high efficiency applications. Therefore, an aperture-coupled antenna with single $\mathrm{CP}$ characteristics has received great attention [6]-[9].

In this paper, a novel compact aperture-coupled circularly polarized antenna for $5.8 \mathrm{GHz}$ WLAN applications was proposed. The X-shaped slot rotated by $45^{\circ}$ with unequal arms etched on a circular microstrip antenna fed through the coupling between the ring slot and the microstrip line. The circular polarization is obtained by cutting two unequal slots in the circular patch.

This paper is organized as follows. In Section 2, the design of the proposed antenna is described. Section 3 presents simulated results. Finally, concluding remarks are given in the last Section.

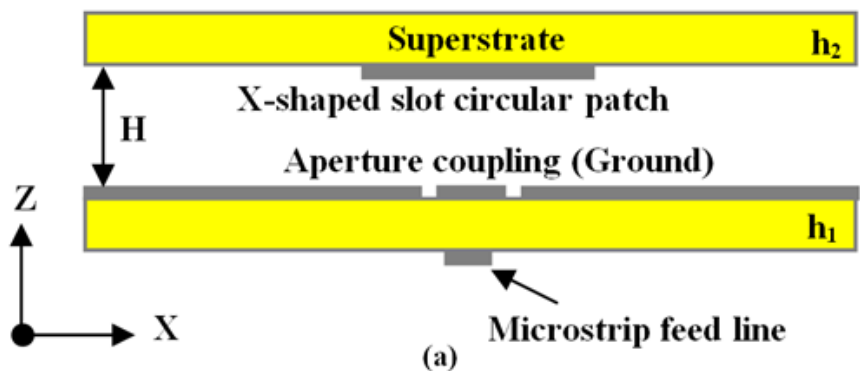




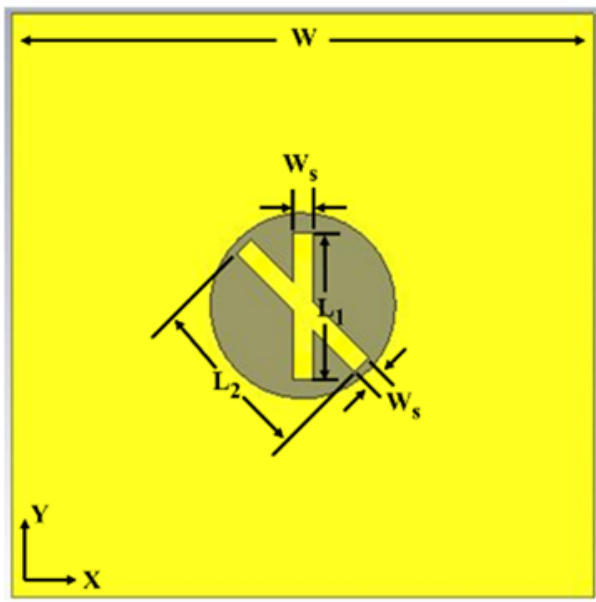

(b)

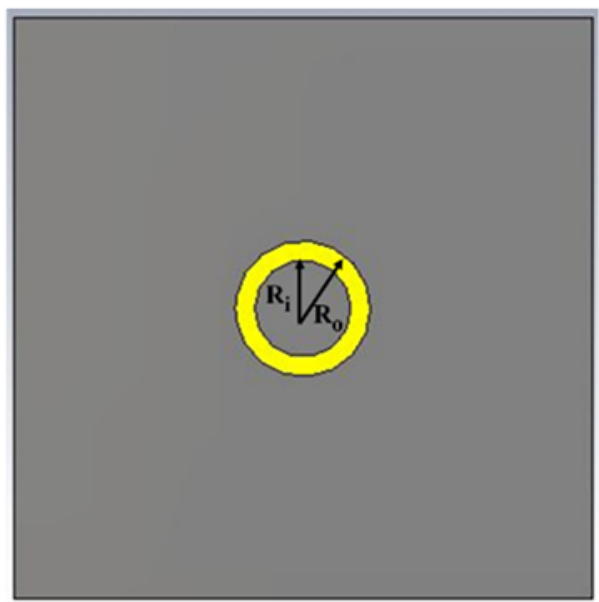

(c)

(d)

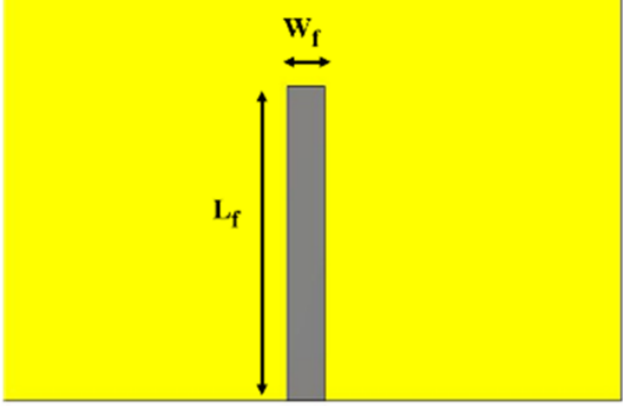

Fig. 1. Geometry of the proposed antenna (a) side view, (b) Top view of the X-shaped slot circular patch antenna, (c) Top view of the aperture coupling ground, (d) Microstrip feed line.

\section{Antenna Design}

The proposed configurations of the circularly polarized antenna fed by a microstrip-coupled slot is shown in Fig. 1. The ring slot aperture feeding is presented in Fig. $1 \mathrm{c}$.

Fig. $1 \mathrm{~b}$ shows the $\mathrm{X}$-shaped slot rotated by $45^{\circ}$ with unequal arms, width Ws, length L1 and L2 is etched in the circular patch. The ring slot with outer radius Ro and inner radius Ri with the microstrip feed line are etched on a Rogers RO4003C substrate of thickness h1 and relative permittivity $\varepsilon$. The $50-\Omega$ microstrip feed line with length $\mathrm{Lf}$ and width Wf is located at the center of the bottom side of the ground plane and is electromagnetically coupled the energy to the ring slot. Moreover, the aperture feed is employed to excite directly the X-shaped circular patch. An optimum air gap height of Hc between the X-shaped slot circular antenna substrate and aperture-coupled substrate is optimized. The aperture-coupled substrate is identical to the one employed for the $\mathrm{X}$-shaped slot circular antenna, the Rogers RO4003C $(\varepsilon \mathrm{r}=3.38, \tan \delta=0.0027)$. The detailed dimensions shown in Fig. 1 are $\mathrm{W} \times \mathrm{L}=60 \times 60 \mathrm{~mm} 2, \mathrm{~L} 1=15 \mathrm{~mm}, \mathrm{~L} 2=17 \mathrm{~mm}, \mathrm{Ws}=2 \mathrm{~mm}, \mathrm{Wf}=3.55 \mathrm{~mm}, \mathrm{Lf}=30 \mathrm{~mm}, \mathrm{~h} 1=$ $1.524 \mathrm{~mm}, \mathrm{~h} 2=0.81 \mathrm{~mm}, \mathrm{Hc}=3.5 \mathrm{~mm}, \mathrm{Ri}=5 \mathrm{~mm}, \mathrm{Ro}=7 \mathrm{~mm}$ and the radius of the circular slot patch is $\mathrm{R}=$ $9.5 \mathrm{~mm}$.

The feed location, the ring slot and the dimensions of X-shaped slot were optimized to give good impedance matching and circular polarization. 


\section{Simulated Results}

Fig. 2 and 3 show the parametric analysis of the return loss (S11) and the Axial Ratio (AR) versus the Xshaped slot L1 and L2, within the operating frequency band. The proposed antenna characteristics were optimized by using the CST MWS [10]. Fig. 2 presents the variation of return loss with L1>L2, L1=L2 and $\mathrm{L} 1<\mathrm{L} 2$. The $-10 \mathrm{~dB} \mathrm{~S} 11$ bandwidth improves as L1<L2 and the impedance matching also improves and gets even better, with an impedance bandwidth of $1.7 \mathrm{GHz}$ (from $4.8 \mathrm{GHz}$ to $6.5 \mathrm{GHz}$ ) which is about 30\%. Fig. 3 shows the variation of $\mathrm{AR}$ at broadside, with $\mathrm{L} 1>\mathrm{L} 2, \mathrm{~L} 1=\mathrm{L} 2$ and $\mathrm{L} 1<\mathrm{L} 2$. The minimum $\mathrm{AR}$ improves when the $\mathrm{L} 1<\mathrm{L} 2$ with a $3 \mathrm{~dB}$ bandwidth of $3.47 \%(5.67-5.87 \mathrm{GHz})$ and a minimum AR value of $1.83 \mathrm{~dB}$ at $5.8 \mathrm{GHz}$.

Fig. 4 presents the simulated S11 and the gain of the proposed antenna. It can be observed that a wideband reflection coefficient with a $10-\mathrm{dB}$ impedance bandwidth of $1.7 \mathrm{GHz}(4.8-6.5 \mathrm{GHz})$ is achieved.

It is illustrated that the $3-\mathrm{dB}$ gain bandwidth is about $46.62 \%(4.08-6.56 \mathrm{GHz})$, with a maximum gain of 8.85 $\mathrm{dBi}$. The common bandwidth for 10- $\mathrm{dB}$ impedance and $3-\mathrm{dB}$ gain is about $30 \%(4.8-6.5 \mathrm{GHz})$.

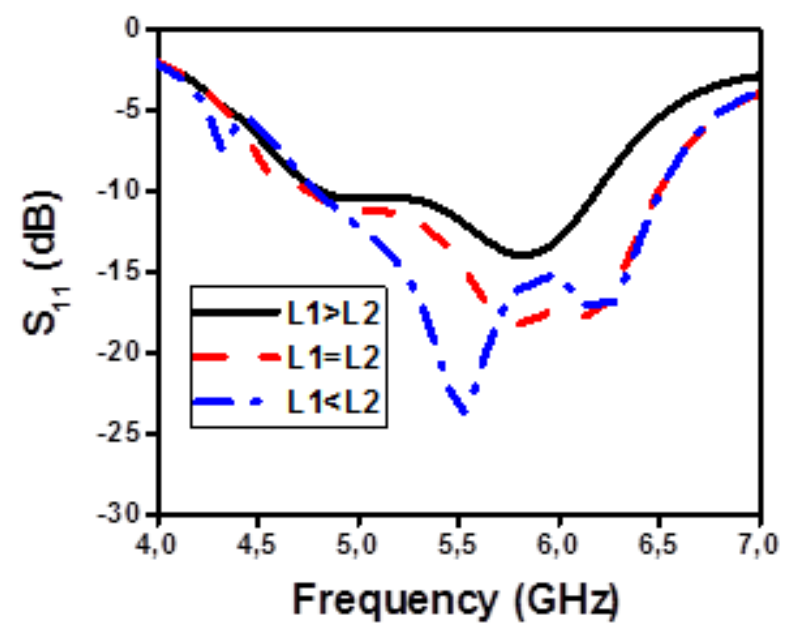

Fig. 2. Simulated $\mathrm{S}_{11}$ of the antenna with $\mathrm{L}_{1}>\mathrm{L}_{2} \mathrm{~L}_{1}=\mathrm{L}_{2}$ and $\mathrm{L}_{1}<\mathrm{L}_{2}$.

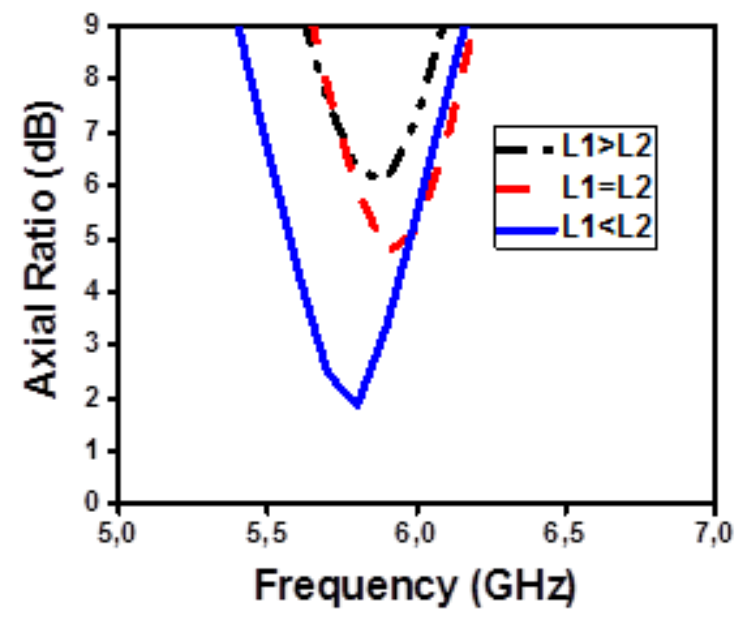

Fig. 3. Simulated $A R$ of the antenna with $\mathrm{L}_{1}>\mathrm{L}_{2}, \mathrm{~L}_{1}=\mathrm{L}_{2}$ and $\mathrm{L}_{1}<\mathrm{L}_{2}$.

The simulated axial ratio AR is shown in Fig. 5. It can be seen that the lowest value of axial ratio is $1.83 \mathrm{~dB}$ at $5.8 \mathrm{GHz}$ that supports WLAN bands. The 3-dB AR bandwidth is $3.47 \%(5.67-5.87 \mathrm{GHz})$ which is still located within the impedance bandwidth of the proposed antenna. 


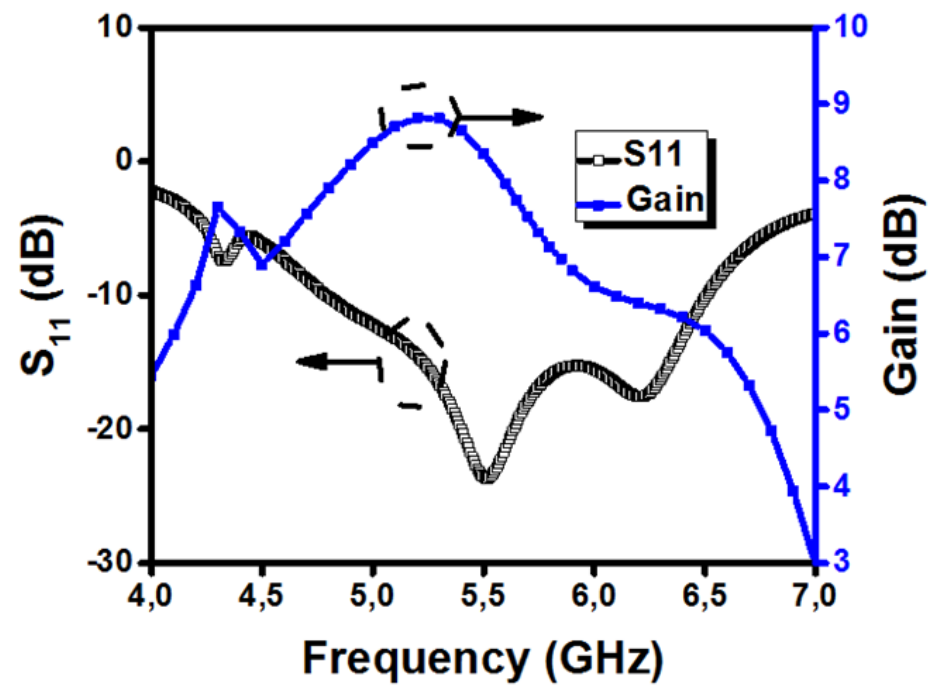

Fig. 4. Simulated results of $S_{11}$ and gain of the antenna.

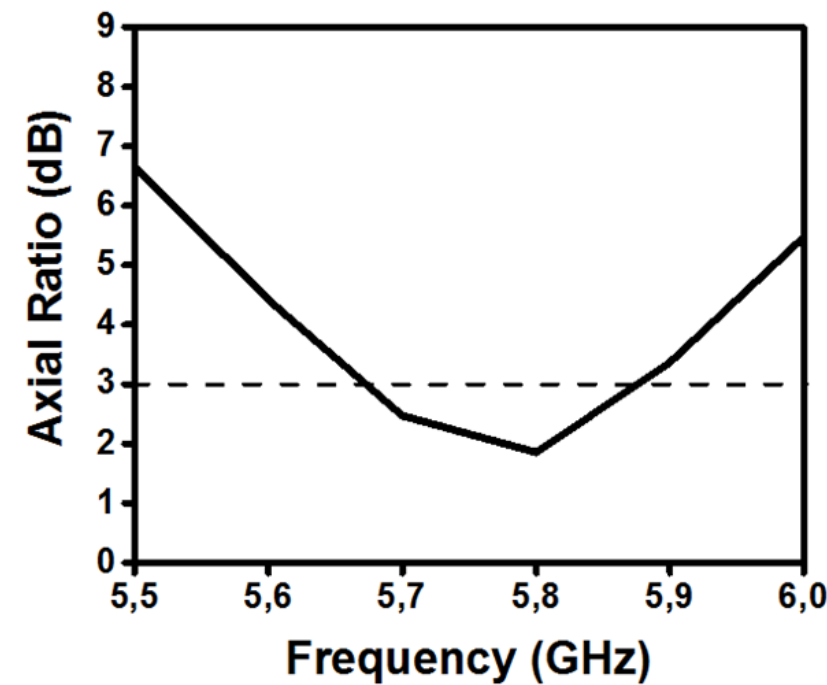

Fig. 5. Simulated AR of the antenna.
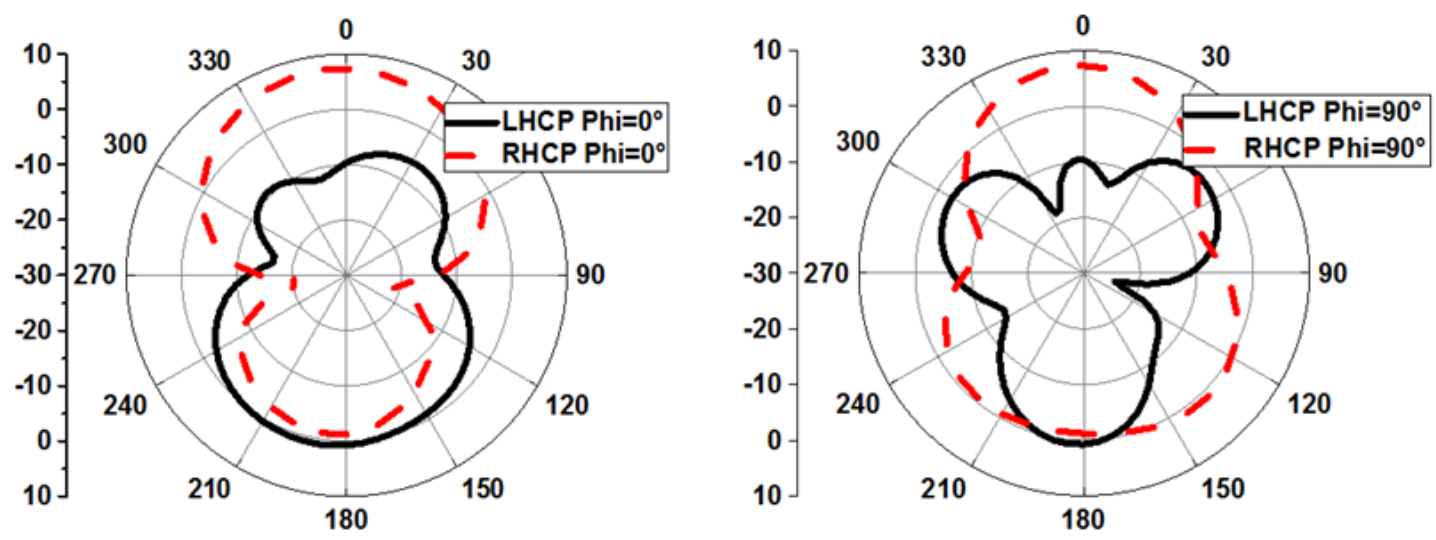

(a) 

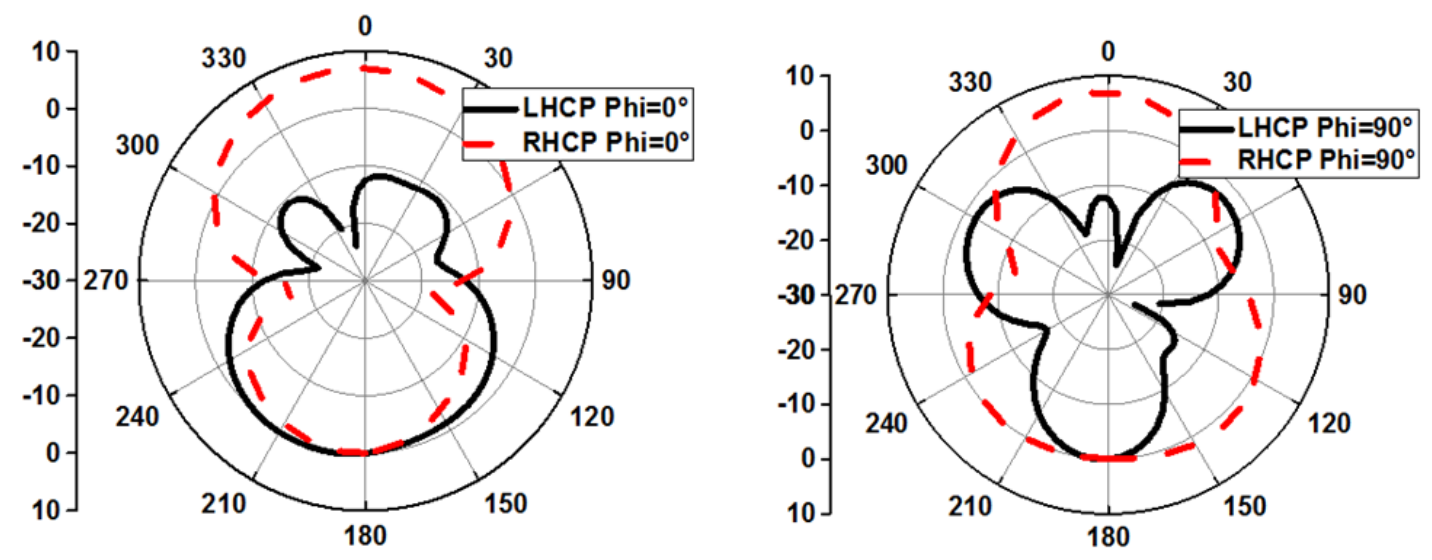

(b)

Fig. 6. Simulated radiation patterns of the antenna at (a) $5.75 \mathrm{GHz}$ and (b) $5.8 \mathrm{GHz}$.

Fig. 6 shows the simulated radiation patterns for both right-hand circular polarization (RHCP) and left-hand circular polarization ( $\mathrm{LHCP}$ ) at $5.75 \mathrm{GHz}$ and $5.8 \mathrm{GHz}$ for phi $=0^{\circ}$ and phi $=90^{\circ}$ planes. It can be observed that the $\mathrm{RHCP}$ is radiated in the $+\mathrm{Z}$ direction, whilst $\mathrm{LHCP}$ in the $-\mathrm{Z}$ direction.

\section{Conclusion}

A novel compact aperture-coupled circularly polarized (CP) antenna for WLAN applications has been presented. The reported results have demonstrated that the circular polarization is obtained by employing the Xshaped slot rotated by $45^{\circ}$ with unequal arms etched on a circular microstrip antenna. Furthermore, the air gap in between the X-shaped slot antenna substrate and the ground plane substrate was used to maintain the gain of the proposed antenna. Consequently, the 10-dB impedance bandwidth of $30 \%(4.8-6.5 \mathrm{GHz})$ is well overlapped by the 3-dB gain bandwidth of $46.62 \%(4.08-6.56 \mathrm{GHz})$. The antenna has a maximum gain of $8.85 \mathrm{dBi}$ and a $3 \mathrm{~dB}$ AR bandwidth of $3.47 \%(5.67-5.87 \mathrm{GHz})$ which is still located within the operating frequency band.

\section{References}

[1] Z-G. Liu, Z-X. Cao, and L.N. Wu, "Compact low-profile circularly polarized fabry-perot resonator antenna fed by linearly polarized microstrip patch,” IEEE Antennas Wireless Propag. Lett., vol. 15, pp. 524-527, 2016.

[2] R.K. Saini, and S. Dwari, "A broadband dual circularly polarized square slot antenna," IEEE Trans Antennas Propag., vol. 64, No. 1, pp. 290-294, January 2016.

[3] M. Ghahremani, Ch. Ghobadi, J. Nourinia, M. Karamirad, and B. Mohammadi, "A novel circularly polarized modified slot MIMO antenna for WLAN applications," Microwave \& Opt. Tech. Letters., vol. 59, No. 4, pp. 876-880, April 2017.

[4] M. Kalhor, J. Nourinia, Ch Ghobadi, M. Akbari, N. Felegari, "Circularly polarized antenna for WLAN and WiMAX applications," International Journal of RF and Microwave Computer-Aided Engineering., vol. 22, No. 3, pp. 329-335 May 2012.

[5] M. A. Choubar, S. Gupta, M. Farahani, A. R. Sebak, T. A. Denidni. "Gain enhancement of circularly-polarized dielectric resonator antenna based on FSS superstrate for MMW applications", IEEE Trans Antennas Propag., vol. 64, No. 12, pp. 5542-5546, December 2016.

[6] Nasimuddin, Z.N. Chen, "Aperture-coupled asymmetrical C-shaped slot microstrip antenna for circular polarisation," IET Microw. Antennas Propag., vol. 3, Iss. 3, pp. 372-378, 2009.

[7] J.-S. Row. "Design of aperture-coupled annular-ring microstrip antennas for circular polarization", IEEE Trans Antennas Propag., vol. 53, No. 5, pp. 1779-1794, May 2005 
[8] J-C. Liu, B-H. Zeng, L. Badjie, S. Drammeh, S-S. Bor, T-F. Hung, and D-Ch. Chang, "Single-feed circularly polarized aperture-coupled stack antenna with dual-mode square loop radiator," IEEE Antennas Wireless Propag. Lett., vol. 9, pp. 887-890, 2010.

[9] Y.-T. Chen, S.-W. Wu and J.-S. Row, "Broadband circularly-polarised slot antenna array," Electron. Lett., vol. 43, no. 24, November 2007.

[10] CST Microwave Studio, Computer Simulation Technology, version 2016. 